\title{
Effects of vildagliptin as add-on treatment in patients with type 2 diabetes mellitus: insights from long-term clinical studies in Japan
}

Masato Odawara ${ }^{1 *}$ and Rieko Sagara ${ }^{2}$

\begin{abstract}
Background: Vildagliptin, a dipeptidyl peptidase-4 (DPP-4) inhibitor, is wildly used to treat type 2 diabetes mellitus (T2DM) with mono- or combination-therapy. We review two previously published open-label studies to extract insights on the long-term efficacy and safety of vildagliptin.

Methods: Two studies were conducted in Japan to assess the efficacy and safety of vildagliptin as an add-on to other oral antidiabetes drugs (OADs) for 52 weeks. These studies were performed under the similar protocol in Japanese patients with T2DM who were inadequately controlled with OAD monotherapy [excluding other dipeptidyl peptidase-4 (DPP-4) inhibitors].

Results: Addition of vildagliptin (50 mg twice daily) to other OAD monotherapy [sulfonylurea (SU), metformin, thiazolidinedione, alpha-glucosidase inhibitor and glinide] reduced glycated hemoglobin ( $\mathrm{HbA} \mathrm{C} \mathrm{c}$ ) levels by -0 . $64 \%,-0.75 \%,-0.92 \%,-0.94 \%$ and $-0.64 \%$, respectively, over 52 weeks of treatment. Overall, the incidence of hypoglycemia was low and was slightly higher in the add-on to SU treatment group compared with the other groups. The incidences of adverse events were comparable among the treatment groups, and vildagliptin was well-tolerated as add-on therapy to other OADs.
\end{abstract}

Conclusions: The evidence from the two studies indicates that vildagliptin as an add-on therapy to other OADs is a clinically reasonable option for Japanese patients with T2DM who respond inadequately to other OAD monotherapy.

Keywords: Combination therapy, Dipeptidyl peptidase-4 inhibitor, Long-term administration, Oral antidiabetes drugs, Vildagliptin

\section{Background}

The Japanese guideline [1] and the international guidelines [2] for management of patients with type 2 diabetes mellitus (T2DM) recommend maintaining tight glycemic control to suppress aggravation and/or occurrence of vascular complications, providing that tight glycemic control can be achieved without hypoglycemia or other significant adverse effects. The

\footnotetext{
* Correspondence: odawara@tokyo-med.ac.jp

${ }^{1}$ The Department of Diabetology, Endocrinology, Metabolism and Rheumatology, Tokyo Medical University, 6-7-1, Nishi-Shinjuku, Shinjuku-ku, Tokyo 160-0023, Japan

Full list of author information is available at the end of the article
}

Japanese Diabetes Society (JDS) recommends glycated hemoglobin $(\mathrm{HbA} 1 \mathrm{c})<7.0$ \% [National Glycohemoglobin Standardization Program (NGSP)] as a general glycemic goal for patients with T2DM. However, many patients in Japan do not achieve this goal [3, 4]. For people with diabetes who do not achieve glycemic control with lifestyle changes including diet and exercise, the JDS recommends treatment with oral antidiabetes drugs (OADs) that should be selected based on the individual patients' clinical profile. Furthermore, for patients inadequately controlled on monotherapy, the guideline recommends combination therapy with a second drug having a different mode of action [1]. 
Treatment with dipeptidyl peptidase-4 (DPP-4) inhibitor as monotherapy has been used in Japan since 2009, and recently patients are increasingly being treated with combination of DPP-4 inhibitors and other OADs [3, 5]. DPP-4 inhibitors maintain the concentrations of incretins, glucagon-like peptide-1 (GLP-1) and glucose-dependent insulinotropic polypeptide, especially during the postprandial period. Thus, like GLP-1 receptor agonists, DPP-4 inhibitors reduce fasting and postprandial blood glucose levels through the effect of incretins on increasing the $\alpha$ and $\beta$-cell sensitivity to glucose levels $[6,7]$. DPP-4 inhibitors are generally weight-neutral and have a low risk of hypoglycemia. They are not also associated with the adverse gastrointestinal effects reported with GLP-1 receptor agonists [8].

Vildagliptin, a DPP-4 inhibitor, was launched in Japan in 2010. In large global studies with a predominantly Caucasian population, vildagliptin has been demonstrated to be well tolerated and efficacious, as monotherapy and in combination with metformin (Met), sulfonylurea (SU), thiazolidinedione (TZD), or insulin [9-13]. Some reports suggested that Asian patients with T2DM have a more prominent insulin secretory defect than Caucasian patients [14]. Also, Japanese regulatory requirements [15] mandated that the indication for combination therapy with other OADs should be supported with data from the Japanese population; this is to ensure there are no marked differences in the safety and efficacy profiles of OADs drugs among different ethnicities. In a previously published Japanese study, vildagliptin demonstrated stable improvements in HbA1c levels, with relatively low hypoglycemic risk, either as monotherapy or as an add-on to SU for treatment duration of up to 52 weeks [16]. Interestingly, the blood-glucose lowering effect appeared to be numerically better in the Japanese population than in the general global population, which was largely derived from non-Asian populations.

The present study reviewed the results of two openlabel studies $[16,17]$ to provide insights on the long-term efficacy and safety of vildagliptin in combination with other OADs in Japanese patients with T2DM with inadequate glycemic control on OAD monotherapy. These studies have been previously published in Japanese.

\section{Methods}

Two multicenter, open-label studies were included to evaluate the long-term tolerability and safety of vildagliptin as an add-on to other OAD. Study A, in which vildagliptin was added to $\mathrm{SU}$, was completed in 2007 [16], and Study B, in which vildagliptin was added to other OAD [Met, TZD, glinide, or $\alpha$ - glucosidase inhibitor ( $\alpha-\mathrm{GI})$ ] was completed in 2012 [17]. Inclusion and exclusion criteria were similar in both the studies; patients aged $\geq 20$ years, inadequately controlled [HbA1c (NGSP) $\geq 6.9 \%$ and $\leq 10.5 \%$ and fasting plasma glucose (FPG) $<270 \mathrm{mg} / \mathrm{dL}$ ] with $\mathrm{OAD}$ monotherapy in addition to diet/exercise therapy were enrolled. The common exclusion criteria of the studies were as follows; pregnant or lactating women, patients with a history of type 1DM or secondary DM, acute metabolic complications within past 24 weeks, acute infection within past 4 weeks, abnormal value in clinical testing (aspartate aminotransferase or alanine aminotransferase activities $>2-2.5$ times the upper limit of normal, high level of serum creatinine $>$ $2 \mathrm{mg} / \mathrm{dL}$, or fasting triglyceride $>500-700 \mathrm{mg} / \mathrm{dL}$. After the patient provided written informed consent, vildagliptin [50 mg twice daily (bid)] was administered in addition to OAD for 52 weeks.

For each OAD therapy, changes in HbA1c levels from baseline to 52 weeks or study endpoint were examined. Changes from baseline to endpoint in FPG, fasting insulin, fasting lipids, homeostasis model assessments for $\beta$ cell function (HOMA- $\beta$ ) and insulin resistance (HOMAIR), and body weight were also evaluated. In addition, the proportion of responders, defined as achieving HbA1c $<6.9 \%$ at endpoint or a $\geq 1.0 \%$ and $\geq 0.5 \%$ reduction in HbA1c from baseline to endpoint were calculated. When parameters were not measured at endpoint, missing values were imputed using the last observation carried forward method. No hypothesis testing was performed and the data were summarized descriptively by treatment. Safety analysis included recording of treatment-emergent adverse events (AEs) and serious AEs (SAEs). Both studies were approved by the institutional review board at each institute which participated in the studies and all the subjects enrolled gave written informed consent prior to start of administration of the study drug. Also, the studies were conducted in accordance with the Helsinki declaration and good clinical practices.

\section{Results \\ Patient characteristics}

Baseline characteristics of patients by OAD therapy group are presented in Table 1. Overall, 299 patients were enrolled: 54 were on SU, 58 were on Met, 62 were on TZD, 62 were on $\alpha$-GI, and 63 were on glinide. The mean age was $\sim 60$ years, and the mean body mass index (BMI) was $\sim 25 \mathrm{~kg} / \mathrm{m}^{2}$. For patients treated with $\mathrm{SU}$ (Study A), the mean baseline HbA1c levels and the mean duration of T2DM were numerically higher and longer, respectively, compared with patients in the other OAD groups. As one patient enrolled in the add-on to SU 
Table 1 Patient demographics and baseline characteristics

\begin{tabular}{|c|c|c|c|c|c|}
\hline \multirow{3}{*}{ Parameters } & \multirow{3}{*}{$\begin{array}{l}\text { Study A } \\
\text { SU } \\
n=54\end{array}$} & \multicolumn{4}{|l|}{ Study B } \\
\hline & & Met & TZD & $a-G l$ & Glinide \\
\hline & & $n=58$ & $n=62$ & $n=62$ & $n=63$ \\
\hline \multicolumn{6}{|l|}{ Gender, n (\%) } \\
\hline Men & $39(72.2)$ & $35(60.3)$ & $50(80.6)$ & $42(67.7)$ & $45(71.4)$ \\
\hline Women & $15(27.8)$ & $23(39.7)$ & $12(19.4)$ & $20(32.3)$ & $18(28.6)$ \\
\hline Age (years) & $60.6 \pm 10.24$ & $58.0 \pm 11.06$ & $59.0 \pm 11.24$ & $60.9 \pm 10.41$ & $59.9 \pm 12.10$ \\
\hline BMI $\left(\mathrm{kg} / \mathrm{m}^{2}\right)$ & $24.7 \pm 3.10$ & $26.0 \pm 3.47$ & $26.5 \pm 3.77$ & $24.8 \pm 3.73$ & $25.0 \pm 3.55$ \\
\hline Duration of type 2 diabetes mellitus (years) & $9.1 \pm 6.61$ & $6.8 \pm 5.91$ & $6.6 \pm 4.90$ & $6.9 \pm 5.25$ & $5.7 \pm 4.76$ \\
\hline $\mathrm{HbA1c}(\%)$ & $8.0 \pm 0.71$ & $7.80 \pm 0.87$ & $7.80 \pm 0.91$ & $7.66 \pm 0.76$ & $7.97 \pm 0.89$ \\
\hline Fasting plasma glucose (mg/dL) & $153.6 \pm 28.26$ & $156.1 \pm 32.97$ & $155.5 \pm 32.16$ & $155.2 \pm 28.18$ & $177.7 \pm 51.10$ \\
\hline \multicolumn{6}{|l|}{ GFR (MDRD) category, n (\%) } \\
\hline$>80 \mathrm{~mL} / \mathrm{min} / 1.73 \mathrm{~m}^{2}$ & $48(88.9)$ & $52(89.7)$ & $58(93.5)$ & $52(83.9)$ & $53(84.1)$ \\
\hline$\leq 80 \mathrm{~mL} / \mathrm{min} / 1.73 \mathrm{~m}^{2}$ & $6(11.1)$ & $6(10.3)$ & $4(6.5)$ & $10(16.1)$ & $10(15.9)$ \\
\hline
\end{tabular}

Values are expressed as $\mathrm{n}(\%)$ or mean \pm standard deviation

One of 54 patients enrolled in SU add-on therapy did not receive the study drug (vildagliptin); therefore, 53 patients were analyzed for safety and efficacy

${ }^{a} \mathrm{HbA1c}$ calculated from JDS value to NGSP value: HbA1c (NGSP) $(\%)=1.02 \times \mathrm{HbA1c}$ (JDS) $(\%)+0.25 \%$

a-GI alpha-glucosidase inhibitor, BMI body mass index, GFR glomerular filtration rate, Met metformin

$M D R D$ modification of diet in renal disease, SU sulfonylurea, TZD thiazolidinedione

group did not receive vildagliptin, 53 patients were analyzed for safety and efficacy assessments.

\section{HbA1c}

As shown in Fig. 1, HbA1c decreased rapidly within the initial three months after addition of vildagliptin in all groups, and the time course of change in HbA1c thereafter was similar in all groups. The decrease in HbA1c after 12 weeks of vildagliptin treatment in each group ranged between $0.82 \%-1.09 \%$. At endpoint, HbA1c reductions in the add-on to $\mathrm{SU}$, Met, TZD, $\alpha-\mathrm{GI}$, and glinide, groups were $0.64 \%, 0.75 \%, 0.92 \%, 0.94 \%$, and $0.64 \%$, respectively.

\section{Responders}

The percentage of responders after add-on treatment with vildagliptin is shown in Table 2 . The proportion of patients achieving $\mathrm{HbA} 1 \mathrm{c}<6.9 \%$ ( $\leq 6.9 \%$ for add-on to SU) was relatively low in the add-on to SU group $(34.6 \%)$ and the add-on to glinide group (37.9\%), but was $>50 \%$ in the other OAD groups. The proportion of patients achieving an $\mathrm{HbA1c}$ reduction of $\geq 1.0 \%$ was also low in the add-on to SU group (26.4\%); whereas the proportion in other groups, including the add-on to glinide group was $\sim 40 \%$.

\section{Body weight}

The mean body weight at endpoint was increased slightly in all the groups, however an increase of more than $2 \mathrm{~kg}$ was observed only in the add-on to TZD group (Table 3 ).

\section{FPG, Fasting Insulin, HOMA- $\beta$, HOMA-IR and Fasting} Lipids

After vildagliptin co-administration, mean FPG decreased in all the add-on groups. The baseline FPG level was higher in the add-on to glinide group than in the other OAD groups, and the change from baseline to endpoint was relatively small in the add-on to SU group (Table 4). Fasting insulin levels increased in the add-on to SU group and slightly increased or decreased in other OAD groups. HOMA- $\beta$ increased in all the OAD groups, and the change was greatest in the add-on to SU group. The value change in HOMA-IR increased only in the add-on to SU group and decreased in all the other OAD groups.

As shown in Table 5, triglyceride, and total cholesterol levels decreased from baseline to endpoint in all OAD groups. Low-density lipoprotein cholesterol levels increased in the add-on to SU group and decreased in the other OAD groups. High-density lipoprotein cholesterol levels slightly increased in the add-on to $\alpha$-GI group and decreased in the other OAD groups.

\section{Adverse events}

The incidence of AEs was comparable among the OAD groups: $90.6 \%$ in the add-on to SU group, $94.8 \%$ in the add-on to Met group, $83.9 \%$ in the add-on to TZD group, $85.5 \%$ in the add-on to $\alpha$-GI group, and $82.5 \%$ in the add-on to glinide group (Table 6). The most frequent AE was nasopharyngitis in all the OAD groups. The majority of AEs were mild or moderate in severity and no death was 
A

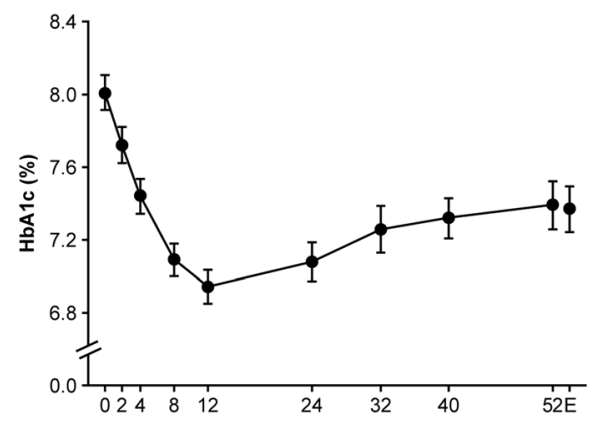

C

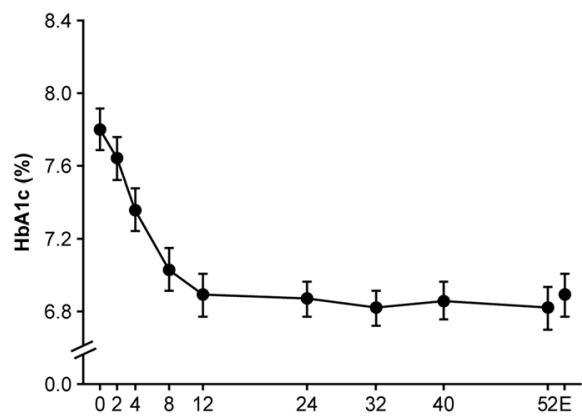

E

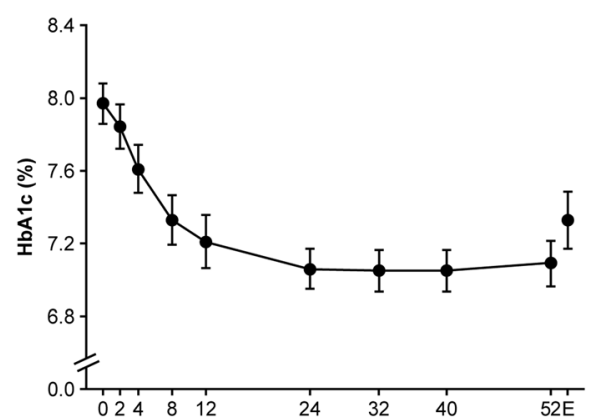

B

Vilda+Met $(n=58)$

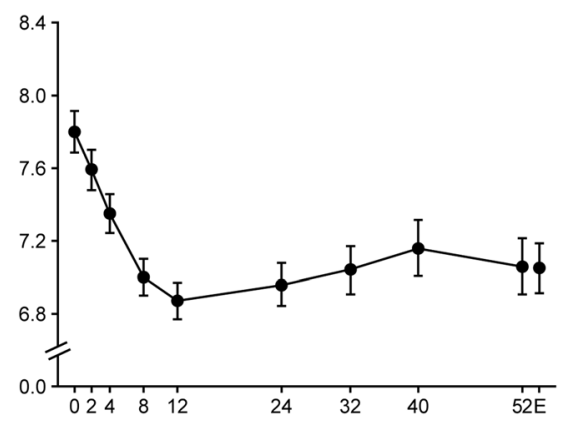

D

Vilda $+\alpha-G I(n=62)$

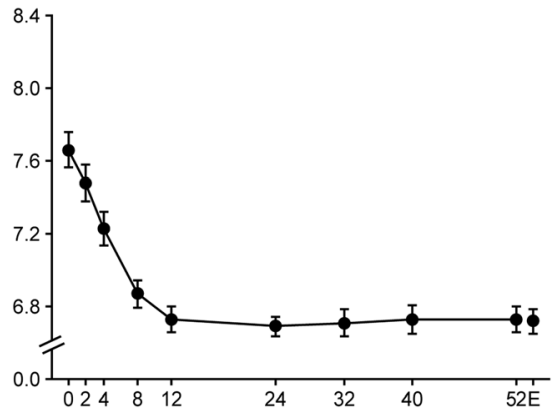

F

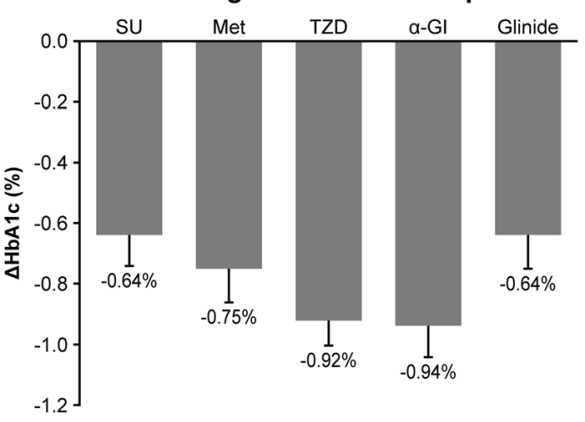

Fig. 1 Time-course change in mean glycated hemoglobin ( $\mathrm{HbA1c}$ ) over 52 weeks in patients with type 2 diabetes mellitus treated with vildagliptin as add-on to other oral antidiabetes drugs. a: Vildagliptin (Vilda) with sulfonylurea (SU), b: Vilda with metformin (Met), c: Vilda with thiazolidinedione (TZD), d: Vilda with a-glucosidase inhibitor (a-Gl), e: Vilda with glinide, f: $\Delta \mathrm{HbA} 1 \mathrm{c}$, change in HbA1c at endpoint; $E$ endpoint. Data are presented as mean \pm standard error

reported during the studies. The incidence of adverse drug reactions was $47.2 \%$ in the add-on to SU group, $29.3 \%$ in the add-on to Met group, $24.2 \%$ in the add-on to TZD group, $12.9 \%$ in the add-on to $\alpha$-GI group and $15.9 \%$ in the add-on to glinide group. At least one episode of hypoglycemic symptoms was reported in 2 patients $(3.8 \%)$ in the add-on to $\mathrm{SU}$ group and 1 patient $(1.7 \%)$ in the add-on to Met group. The hypoglycemic events were moderate in severity and categorized as grade 1 . None of the patients in the TZD, $\alpha-\mathrm{GI}$, or glinide groups reported hypoglycemic events. Discontinuation of treatment due to AEs was overall low, occurred in 4 patients (7.5 \%) in the add-on to SU group, 3 patients (5.2\%) in the add-on to Met group, 4 patients $(6.5 \%)$ in the add-on to TZD group, 4 patients $(6.5 \%)$ in the addon to $\alpha$-GI group, and 6 patients $(9.5 \%)$ in the addon to glinide group.

\section{Discussion}

The efficacy and safety analysis from two long-term 52week studies showed that vildagliptin $50 \mathrm{mg}$ bid, in 
Table 2 Proportion of responders at endpoint

\begin{tabular}{|c|c|c|c|c|c|}
\hline & Study A & Study B & & & \\
\hline & SU & Met & TZD & $a-G l$ & Glinide \\
\hline & $n^{\mathrm{a}}=53$ & $n^{\mathrm{a}}=58$ & $n^{a}=62$ & $n^{a}=62$ & $n^{a}=63$ \\
\hline & $\%(n)$ & $\%(n)$ & $\%(n)$ & $\%(n)$ & $\%(n)$ \\
\hline $\mathrm{HbA} 1 \mathrm{c}<6.9 \%$ or $\leq 6.9 \%^{\mathrm{b}}$ & 34.6 & 53.8 & 59.3 & 69.6 & 37.9 \\
\hline & $(18 / 52)$ & $(28 / 52)$ & $(32 / 54)$ & $(39 / 56)$ & $(22 / 58)$ \\
\hline$\geq 1.0 \%$ reduction in $\mathrm{HbA} 1 \mathrm{c}$ & 26.4 & 46.6 & 41.9 & 43.5 & 38.1 \\
\hline & $(14 / 53)$ & $(27 / 58)$ & $(26 / 62)$ & $(27 / 62)$ & $(24 / 63)$ \\
\hline$\geq 0.5 \%$ reduction in $\mathrm{HbA} 1 \mathrm{c}$ & 60.4 & 69.0 & 74.2 & 80.6 & 61.9 \\
\hline & $(32 / 53)$ & $(40 / 58)$ & $(46 / 62)$ & $(50 / 62)$ & $(39 / 63)$ \\
\hline
\end{tabular}

${ }^{a}$ Number of patients with both baseline and endpoint HbA1c measurements in the specified population, which was used as denominator, unless specified otherwise

${ }^{\mathrm{b}}$ Denominator consists of patients with baseline $\mathrm{HbA} 1 \mathrm{c} \geq 6.9 \%$ and endpoint $\mathrm{HbA} 1 \mathrm{c}$ measurement. In SU group, $\mathrm{HbA} 1 \mathrm{c} \leq 6.9 \%$ was employed as criteria of responder

a-GI alpha-glucosidase inhibitor, Met metformin, SU sulfonylurea, TZD thiazolidinedione

combination with other OADs in Japanese patients with T2DM, exerts robust blood glucose-lowering effects and is well tolerated. There was no remarkable difference in the incidence of AEs among the OADs used as baseline therapy. The risk of hypoglycemia was overall low, with a slight increase in the add-on to SU group. The events were mild in severity and were manageable by the patients.

DPP-4 inhibitors are relatively new drugs among OADs, however, their use in T2DM patients is markedly increasing in the clinical setting. The bloodglucose lowering effect of DPP-4 inhibitor has been well recognized, but only few studies to investigate the differences among DPP-4 inhibitors are available [18]. An indirect comparison adjusted for the background characteristics in Japanese patients with T2DM revealed that the effect of vildagliptin $(50 \mathrm{mg}$ bid) in reducing $\mathrm{HbA1c}$ levels was significantly stronger compared to sitagliptin (50 or $100 \mathrm{mg}$ qd) [19]. Concerning the mode of enzyme inhibition by DPP-4 inhibitors, the inhibition kinetics of vildagliptin was slower than that of sitagliptin [20,21]. This difference in the kinetics of DPP-4 inhibition may be related with the significant suppression of blood glucose fluctuations during $24 \mathrm{~h}$ with vildagliptin compared to sitagliptin [22]. However, HbA1c prior to treatment with DPP-4 inhibitors is strongly associated with the variance of HbA1c reduction in response to DPP-4 inhibitors [23]. The efficacy and safety of vildagliptin in long-term observation has remained to be elucidated thoroughly.

Addition of vildagliptin $50 \mathrm{mg}$ bid resulted in a rapid decrease in HbAlc in all the OAD groups. The combination of vildagliptin and other OADs provided an effective glucose-lowering therapy, but attention should be paid to hypoglycemic events as well as refractoriness in the reduction of HbA1c levels, especially when vildagliptin is administered in combination with insulin secretagogues for an extended period. In the current studies, the degree of $\mathrm{HbA1c}$ reduction by vildagliptin in combination with insulin secretagogues (SU or glinide) was relatively smaller when compared to the combination with non-insulin secretagogues (Met, TZD, or $\alpha-G I$ ).

In addition to hypoglycemia, weight gain is another important issue to be considered while choosing pharmacotherapy for the management of T2DM [24]. In these studies, a $>1 \mathrm{~kg}$ increase in weight was found with the add-on to insulin secretagogues (SU, glinide) and TZD therapy, in contrast to a previous study on sitagliptin, where weight reduction was observed due to a decrease in dose of SU [25]. The increase in body weight in the add-on to insulin secretagogues group is presumably due to defensive eating secondary to the increased tendency to mild hypoglycemia in the SU and glinide groups; in the TZD group it is not clear why the usual increase in weight is exacerbated by the addition of

Table 3 Change in body weight

\begin{tabular}{|c|c|c|c|c|c|}
\hline & \multirow{2}{*}{$\frac{\text { Study A }}{S U}$} & \multicolumn{4}{|l|}{ Study B } \\
\hline & & Met & TZD & $\mathrm{a}-\mathrm{Gl}$ & Glinide \\
\hline & $n=53$ & $n=58$ & $n=62$ & $n=62$ & $n=63$ \\
\hline Baseline (kg) & $66.01 \pm 1.65$ & $68.76 \pm 1.285$ & $72.29 \pm 1.749$ & $65.60 \pm 1.634$ & $66.81 \pm 1.728$ \\
\hline Change at endpoint (kg) & $1.49 \pm 0.26$ & $0.51 \pm 0.330$ & $2.11 \pm 0.318$ & $0.45 \pm 0.323$ & $1.17 \pm 0.281$ \\
\hline
\end{tabular}

Values are expressed mean \pm standard error

a-Gl alpha-glucosidase inhibitor, Met metformin, SU sulfonylurea, TZD thiazolidinedione 
Table 4 Change in fasting plasma glucose, fasting insulin, HOMA- $\beta$ and HOMA - IR

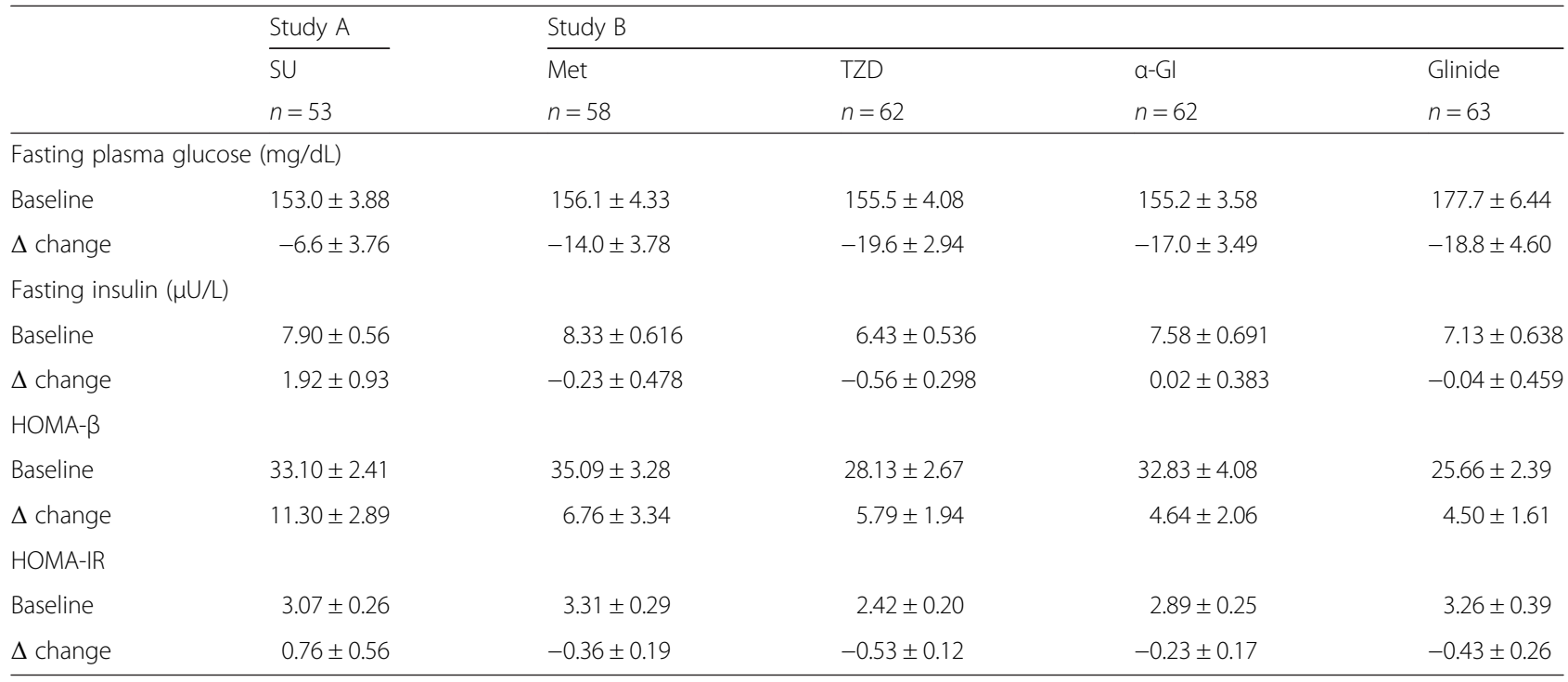

Values are expressed as mean \pm standard error

$\Delta$ change from baseline to endpoint, $\mathrm{a}-\mathrm{Gl}$ alpha-glucosidase inhibitor, HOMA homeostasis model assessment, Met metformin, SU sulfonylurea,

TZD thiazolidinedione

vildagliptin when one considers its mechanisms to mitigate body weight [26].

One limitation of this manuscript is that two independent clinical studies were reviewed in a parallel manner; hence, no statistical analysis was performed to compare efficacy and safety parameters among the different treatment groups. Another limitation is that only combination of vildagliptin with OAD was focused in this article, although it has been reported that vildagliptin as add-on to insulin significantly reduced HbAlc in
Japanese patients with T2DM [27]. Concerning the safety of DPP-4 inhibitors, no studies have revealed that DPP-4 inhibitors provide beneficial outcome on incidence of cardiovascular events, however, meta-analysis have shown that DPP-4 inhibitors have a neutral effect on major cardiovascular events $[28,29]$.

\section{Conclusions}

In conclusion, vildagliptin as an add-on to other OADs in Japanese patients with T2DM results in

Table 5 Change in fasting lipids

\begin{tabular}{|c|c|c|c|c|c|}
\hline & \multirow{3}{*}{$\begin{array}{l}\text { Study A } \\
\text { SU } \\
n=53\end{array}$} & \multicolumn{4}{|l|}{ Study B } \\
\hline & & Met & TZD & $\mathrm{a}-\mathrm{Gl}$ & Glinide \\
\hline & & $n=58$ & $n=62$ & $n=61^{\mathrm{a}}$ & $n=61^{\mathrm{a}}$ \\
\hline \multicolumn{6}{|c|}{ Triglyceride (mg/dL) } \\
\hline Baseline & $137.9 \pm 13.09$ & $158.0 \pm 12.48$ & $131.6 \pm 11.69$ & $150.5 \pm 17.80$ & $155.8 \pm 13.68$ \\
\hline$\Delta$ change & $-6.6 \pm 9.28$ & $-19.4 \pm 11.42$ & $-7.8 \pm 7.93$ & $-12.3 \pm 12.90$ & $-8.7 \pm 10.21$ \\
\hline \multicolumn{6}{|c|}{ Total cholesterol (mg/dL) } \\
\hline Baseline & $197.8 \pm 3.95$ & $195.0 \pm 4.19$ & $199.0 \pm 4.45$ & $200.0 \pm 4.47$ & $206.9 \pm 4.98$ \\
\hline$\Delta$ change & $-3.3 \pm 3.22$ & $-7.1 \pm 2.40$ & $-7.2 \pm 3.74$ & $-5.3 \pm 3.53$ & $-7.6 \pm 3.37$ \\
\hline \multicolumn{6}{|c|}{ Low-density lipoprotein (mg/dL) } \\
\hline Baseline & $123.8 \pm 3.81$ & $115.8 \pm 3.51$ & $115.3 \pm 3.60$ & $122.7 \pm 4.22$ & $126.1 \pm 4.21$ \\
\hline$\Delta$ change & $1.3 \pm 2.77$ & $-0.9 \pm 2.44$ & $-1.5 \pm 3.19$ & $-1.2 \pm 3.31$ & $-2.3 \pm 3.10$ \\
\hline \multicolumn{6}{|c|}{ High-density lipoprotein (mg/dL) } \\
\hline Baseline & $51.5 \pm 1.45$ & $55.4 \pm 1.85$ & $62.5 \pm 2.54$ & $54.1 \pm 1.58$ & $57.2 \pm 1.76$ \\
\hline$\Delta$ change & $-1.8 \pm 0.74$ & $-1.4 \pm 1.03$ & $-2.0 \pm 1.22$ & $0.4 \pm 0.82$ & $-1.1 \pm 1.21$ \\
\hline
\end{tabular}

Values are expressed as mean \pm standard error

${ }^{a}$ Measurements for one patient in the $\mathrm{a}-\mathrm{Gl}$ group and two patients in the glinide group were missing

$\Delta$ change from baseline to endpoint, a-GI alpha-glucosidase inhibitor, Met metformin, SU sulfonylurea, TZD thiazolidinedione 
Table 6 Adverse events

\begin{tabular}{|c|c|c|c|c|c|}
\hline \multirow{3}{*}{$n(\%)$} & \multirow{3}{*}{$\begin{array}{l}\frac{\text { Study A }}{S U} \\
n=53\end{array}$} & \multicolumn{4}{|l|}{ Study B } \\
\hline & & \multirow{2}{*}{$\begin{array}{l}\text { Met } \\
n=58\end{array}$} & \multirow{2}{*}{$\begin{array}{l}\text { TZD } \\
n=62\end{array}$} & \multirow{2}{*}{$\begin{array}{l}a-G 1 \\
n=62\end{array}$} & \multirow{2}{*}{$\begin{array}{l}\text { Glinide } \\
n=63\end{array}$} \\
\hline & & & & & \\
\hline Adverse events (AEs) & $48(90.6)$ & $55(94.8)$ & $52(83.9)$ & $53(85.5)$ & $52(82.5)$ \\
\hline Adverse drug reactions & $25(47.2)$ & $17(29.3)$ & $15(24.2)$ & $8(12.9)$ & $10(15.9)$ \\
\hline Serious AEs & $3(5.7)$ & $4(6.9)$ & $5(8.1)$ & $4(6.5)$ & $2(3.2)$ \\
\hline Discontinuation due to AEs & $4(7.5)$ & $3(5.2)$ & $4(6.5)$ & $4(6.5)$ & $6(9.5)$ \\
\hline Patients with at least one episode of hypoglycemic symptoms & $2(3.8)$ & $1(1.7)$ & $0(0.0)$ & $0(0.0)$ & $0(0.0)$ \\
\hline \multicolumn{6}{|l|}{ AEs by preferred term $>5 \%$} \\
\hline Nasopharyngitis & $25(47.2)$ & $17(29.3)$ & $13(21.0)$ & $25(40.3)$ & $20(31.7)$ \\
\hline Constipation & $4(7.5)$ & $9(15.5)$ & $3(4.8)$ & $4(6.5)$ & $5(7.9)$ \\
\hline Back pain & $8(15.1)$ & $3(5.2)$ & $4(6.5)$ & $5(8.1)$ & $3(4.8)$ \\
\hline Gastritis & $6(11.3)$ & $5(8.6)$ & $4(6.5)$ & $2(3.2)$ & $1(1.6)$ \\
\hline Upper respiratory tract infection & $1(1.9)$ & $3(5.2)$ & $4(6.5)$ & $1(1.6)$ & $4(6.3)$ \\
\hline Dizziness & $5(9.4)$ & $2(3.4)$ & $2(3.2)$ & $2(3.2)$ & $5(7.9)$ \\
\hline Contusion & $1(1.9)$ & $3(5.2)$ & $1(1.6)$ & $1(1.6)$ & $5(7.9)$ \\
\hline Bronchitis & $1(1.9)$ & $5(8.6)$ & $0(0.0)$ & $3(4.8)$ & $1(1.6)$ \\
\hline Edema peripheral & $0(0.0)$ & $1(1.7)$ & $4(6.5)$ & $2(3.2)$ & $1(1.6)$ \\
\hline Blood amylase increased & $3(5.7)$ & $3(5.2)$ & $3(4.8)$ & $2(3.2)$ & $0(0.0)$ \\
\hline Osteoarthritis & $1(1.9)$ & $3(5.2)$ & $3(4.8)$ & $0(0.0)$ & $2(3.2)$ \\
\hline Headache & $1(1.9)$ & $3(5.2)$ & $1(1.6)$ & $1(1.6)$ & $3(4.8)$ \\
\hline Diarrhea & $0(0.0)$ & $5(8.6)$ & $1(1.6)$ & $1(1.6)$ & $0(0.0)$ \\
\hline Hunger & $7(13.2)$ & $3(5.2)$ & $1(1.6)$ & $1(1.6)$ & $2(3.2)$ \\
\hline Hypoesthesia & $1(1.9)$ & $0(0.0)$ & $3(4.8)$ & $0(0.0)$ & $4(6.3)$ \\
\hline Conjunctivitis allergic & $0(0.0)$ & $4(6.9)$ & $0(0.0)$ & $0(0.0)$ & $2(3.2)$ \\
\hline Periodontitis & $0(0.0)$ & $0(0.0)$ & $1(1.6)$ & $4(6.5)$ & $1(1.6)$ \\
\hline Dry eye & $0(0.0)$ & $0(0.0)$ & $4(6.5)$ & $0(0.0)$ & $1(1.6)$ \\
\hline C-reactive protein increased & $2(3.8)$ & $4(6.9)$ & $0(0.0)$ & $0(0.0)$ & $1(1.6)$ \\
\hline Arthralgia & $3(5.7)$ & $3(5.2)$ & $1(1.6)$ & $0(0.0)$ & $1(1.6)$ \\
\hline Pharyngitis & $1(1.9)$ & $10(17.2)$ & $3(4.8)$ & $1(1.6)$ & $1(1.6)$ \\
\hline Blood creatine phosphokinase increased & $7(13.2)$ & $2(3.4)$ & $2(3.2)$ & $1(1.6)$ & $1(1.6)$ \\
\hline Tremor & $7(13.2)$ & $1(1.7)$ & $1(1.6)$ & $0(0.0)$ & $0(0.0)$ \\
\hline Asthenia & $6(11.3)$ & $2(3.4)$ & $0(0.0)$ & $2(3.2)$ & $2(3.2)$ \\
\hline Blood creatine phosphokinase MB increased & $5(9.4)$ & $2(3.4)$ & $1(1.6)$ & $1(1.6)$ & $0(0.0)$ \\
\hline Hyperhidrosis & $4(7.5)$ & $2(3.4)$ & $0(0.0)$ & $0(0.0)$ & $2(3.2)$ \\
\hline Hypertension & $3(5.7)$ & $2(3.4)$ & $2(3.2)$ & $2(3.2)$ & $2(3.2)$ \\
\hline Eczema & $3(5.7)$ & $2(3.4)$ & $2(3.2)$ & $2(3.2)$ & $2(3.2)$ \\
\hline Myalgia & $3(5.7)$ & $1(1.7)$ & $1(1.6)$ & $0(0.0)$ & $1(1.6)$ \\
\hline Palpitations & $3(5.7)$ & $1(1.7)$ & $1(1.6)$ & $3(4.8)$ & $1(1.6)$ \\
\hline Anemia & $3(5.7)$ & $1(1.7)$ & $0(0.0)$ & $2(3.2)$ & $0(0.0)$ \\
\hline
\end{tabular}

a-Gl alpha-glucosidase inhibitor, Met metformin, SU sulfonylurea, TZD thiazolidinedione

robust decrease in HbA1c levels with good tolerability and low risk of hypoglycemia and weight gain. Vildagliptin improved glucose metabolism regardless of the type of OADs combined with vildagliptin.
Vildagliptin is considered to be a clinically reasonable treatment option with good tolerability profile for patients with T2DM responding inadequately to other OADs. 


\section{Abbreviations}

AEs, Adverse events; BMI, Body mass index; DPP-4, Dipeptidyl peptidase-4; E Endpoint; GFR, Glomerular filtration rate; GLP-1, Glucagon-like peptide-1; HbA1c, Glycated hemoglobin; HOMA-IR, Homeostasis model assessments for insulin resistance; HOMA- $\beta$, Homeostasis model assessments for $\beta$-cell function; JDS, Japanese Diabetes Society; MDRD, modification of diet in renal disease; Met, Metformin; NGSP, National Glycohemoglobin Standardization Program; OADs, Oral antidiabetes drugs; SAEs, Serious adverse events; SU, Sulfonylurea; T2DM, Type 2 diabetes mellitus; TZD, Thiazolidinedione; a-Gl, a-glucosidase inhibitor

\section{Acknowledgments}

The authors thank Amit Garg and Abhilasha Verma (Novartis Healthcare Private Limited, Hyderabad, India) for editorial assistance.

\section{Funding}

No sources of support provided for this paper. Two clinical studies that were compiled in this paper were conducted by the sponsorship of Novartis Pharma KK.

\section{Availability of data and materials}

Available on request.

\section{Authors' contributions}

MO made intellectual contributions to the manuscript, and RS contributed to drafting and critical revision of the manuscript. All the authors meet the ICMJE criteria for authorship, participated at all stages of manuscript development and approved the final manuscript for publication. Authors had full access to all of the data and take complete responsibility for the integrity of the data. Both authors read and approved the final manuscript.

\section{Competing interests}

There was no conflict of interest to be stated. Masato Odawara is the medical adviser for one of the two clinical studies that were compiled in this paper. Rieko Sagara is an employee at Novartis Pharm K.K.

\section{Consent for publication}

Not Applicable.

\section{Ethics approval and consent to participate}

This is a review based on two studies which were carried out in human participants. The studies were approved by the institutional review board in each institute participated to the studies. All the subjects enrolled provided written informed consent prior to administration of the study drug in the studies. The studies were conducted in accordance with the Helsinki declaration and good clinical practices.

\section{Author details}

${ }^{1}$ The Department of Diabetology, Endocrinology, Metabolism and Rheumatology, Tokyo Medical University, 6-7-1, Nishi-Shinjuku, Shinjuku-ku, Tokyo 160-0023, Japan. ${ }^{2}$ Medical Division, Novartis Pharm K.K, Toranomon Hills Mori Tower, 23-1, Toranomon 1-chome, Minato-ku 105-6333, Tokyo, Japan.

Received: 3 March 2016 Accepted: 12 June 2016

Published online: 04 July 2016

\section{References}

1. Treatment Guide for Diabetes 2012-2013. the Japan Diabetes Society. Bunkodo Co. Ltd. 2013

2. Inzucchi SE, Bergenstal RM, Buse JB, Diamant M, Ferrannini E, Nauck M, et al. Management of hyperglycemia in type 2 diabetes, 2015: a patient centered approach: update to a position statement of the American Diabetes Association and the European Association for the Study of Diabetes. Diabetes Care. 2015;38:140-9.

3. Oishi M, Yamazaki K, Okuguchi F, Sugimoto H, Kanatsuka A, Kashiwagi A Japan Diabetes Clinical Data Management Study Group. Changes in oral antidiabetic prescriptions and improved glycemic control during the years 2002-2011 in Japan (JDDM32). J Diabetes Invest. 2014:5:581-7.

4. Japan Diabetes Clinical Data Management Study Group (JDDM). Available at: http://jddm.jp/data/index.html (Last accessed, 2nd Feb, 2016).
5. Namba M, Katsuno T, Kusunoki Y, Matsuo T, Miuchi M, Miyagawa J. New strategy for the treatment of type 2 diabetes mellitus with incretin-based therapy. Clin Exp Nephrol. 2013;17:10-5.

6. Drucker DJ, Nauck MA. The incretin system: glucagon-like peptide-1 receptor agonists and dipeptidyl peptidase-4 inhibitors in type 2 diabetes. Lancet. 2006:368:1696-705.

7. Kim W, Egan JM. The role of incretins in glucose homeostasis and diabetes treatment. Pharmacol Rev. 2008:60:470-512

8. Krentz AJ, Patel MB, Bailey CJ. New drugs for type 2 diabetes mellitus: what is their place in therapy? Drugs. 2008;68:2131-62.

9. Pi-Sunyer FX, Schweizer A, Mills D, Dejager S. Efficacy and tolerability of vildagliptin monotherapy in drug-naive patients with type 2 diabetes. Diabetes Res Clin Pract. 2007:76:132-8.

10. Bosi E, Camisasca RP, Collober C, Rochotte E, Garber AJ. Effects of vildagliptin on glucose control over 24 weeks in patients with type 2 diabetes inadequately controlled with metformin. Diabetes Care. 2007;30:890-5

11. Garber AJ, Foley JE, Banerji MA, Ebeling P, Gudbjörnsdottir S, Camisasca RP, et al. Effects of vildagliptin on glucose control in patients with type 2 diabetes inadequately controlled with a sulphonylurea. Diabetes Obes Metab. 2008;10:1047-56.

12. Garber AJ, Schweizer A, Baron MA, Rochotte E, Dejager S. Vildagliptin in combination with pioglitazone improves glycaemic control in patients with type 2 diabetes failing thiazolidinedione monotherapy: a randomized, placebo-controlled study. Diabetes Obes Metab. 2007;9:166-74.

13. Kothny W, Foley J, Kozlovski P, Shao Q, Gallwitz B, Lukashevich V. Improved glycaemic control with vildagliptin added to insulin, with or without metformin, in patients with type 2 diabetes mellitus. Diabetes Obes Metab. 2013;15:252-7

14. Kim YG, Hahn S, Oh TJ, Kwak SH, Park KS, Cho YM. Differences in the glucose-lowering efficacy of dipeptidyl peptidase-4 inhibitors between Asians and non-Asians: a systematic review and meta-analysis. Diabetologia. 2013;56:696-708.

15. Ministry of Health, Labour and Welfare. Guideline for clinical evaluation of oral hypoglycemic agents. Issued on 9th July 2011. Available at: http://www pmda.go.jp/files/000153859.pdf (Last accessed, 2nd Feb 2016).

16. Kikuchi M, Utsunomiya K, Moriya T, Terao S, Kitawaki T, Mimori N, et al. Long-term evaluation of vildagliptin in patients with type 2 diabetes; mono or combination with sulfonylurea therapy for 52 weeks. J New Rem Clin. 2010:59:137-54 (in Japanese).

17. Odawara M, Suzuki M, Hamada I, Iguchi S. Clinical evaluation of combination therapy with vildagliptin in patients with type 2 diabetes; safety of add-on to metformin, thiazolidine, $\mathrm{a}-\mathrm{Gl}$ or glinide for 52 weeks. J New Rem Clin. 2012;61:2593-611 (in Japanese).

18. Madsbad S, Krarup T, Deacon CF, Holst JJ. Glucagon-like peptide receptor agonists and dipeptidyl peptidase-4 inhibitors in the treatment of diabetes: a review of clinical trials. Curr Opin Clin Nutr Metab Care. 2008:11:491-9.

19. Signorovitch JE, Wu EQ, Swallow E, Kantor E, Fan L, Gruenberger JB. Comparative efficacy of vildagliptin and sitagliptin in Japanese patients with type 2 diabetes mellitus: a matching-adjusted indirect comparison of randomized trials. Clin Drug Investig. 2011;31:665-74.

20. Davis JA, Singh S, Sethi S, Roy S, Mittra S, Rayasam G, et al. Nature of action of Sitagliptin, the dipeptidyl peptidase-IV inhibitor in diabetic animals. Indian J Pharmacol. 2010;42:229-33.

21. Ahrén B, Schweizer A, Dejager S, Villhauer EB, Dunning BE, Foley JE. Mechanisms of action of the dipeptidyl peptidase-4 inhibitor vildagliptin in humans. Diabetes Obes Metab. 2011;13:775-83.

22. Sakamoto M, Nishimura R, Irako T, Tsujino D, Ando K, Utsunomiya K. Comparison of vildagliptin twice daily vs. sitagliptin once daily using continuous glucose monitoring (CGM): crossover pilot study (J-VICTORIA study). Cardiovasc Diabetol. 2012;11:92.

23. Esposito K, Chiodini P, Maiorino MI, Capuano A, Cozzolino D, Petrizzo M et al. A nomogram to estimate the $\mathrm{HbA1c}$ response to different DPP-4 inhibitors in type 2 diabetes: a systematic review and meta-analysis of 98 trials with 24163 patients. BMJ Open. 2015;5, e005892.

24. Phung OJ, Scholle JM, Talwar $\mathrm{M}$, Coleman $\mathrm{Cl}$. Effect of noninsulin antidiabetic drugs added to metformin therapy on glycemic control, weight gain, and hypoglycemia in type 2 diabetes. JAMA. 2010;303:1410-8.

25. Kubota A, Maeda H, Kanamori A, Atoba K, Jin Y, Minagawa F, et al. Efficacy and safety of sitagliptin monotherapy and combination therapy in Japanese type 2 diabetes patients. J Diabetes Invest. 2012;3:503-9. 
26. Foley JE, Jordan J. Weight neutrality associated with the DPP-4 inhibitor, vildagliptin: mechanistic basis and clinical experience. Vasc Health Risk Manag. 2010;6:541-8.

27. Hirose T, Suzuki M, Tsumiyama I. Efficacy and Safety of Vildagliptin as an Add-on to Insulin with or without Metformin in Japanese Patients with Type 2 Diabetes Mellitus: A 12-week, Double-Blind, Randomized Study. Diabetes Ther. 2015;6:559-71.

28. Savarese G, Perrone-Filardi P, D'Amore C, Vitale C, Trimarco B, Pani L, et al. Cardiovascular effects of dipeptidyl peptidase-4 inhibitors in diabetic patients: A meta-analysis. Int J Cardiol. 2015;181:239-44.

29. Abbas AS, Dehbi HM, Ray KK. Cardiovascular and non-cardiovascular safety of dipeptidyl peptidase-4 inhibition: a meta-analysis of randomized controlled cardiovascular outcome trials. Diabetes Obes Metab. 2016;18: 295-9.

Submit your next manuscript to BioMed Central and we will help you at every step:

- We accept pre-submission inquiries

- Our selector tool helps you to find the most relevant journal

- We provide round the clock customer support

- Convenient online submission

- Thorough peer review

- Inclusion in PubMed and all major indexing services

- Maximum visibility for your research

Submit your manuscript at www.biomedcentral.com/submit
Biomed Central 